\title{
DESAFIOS DA GESTÃO DA ESCOLA DE TEMPO INTEGRAL
}

\author{
CHALLENGES OF MANAGEMENT OF FULL-TIME SCHOOL
}

DESAFÍOS DE LA GESTIÓN DE LA ESCUELA DE TIEMPO INTEGRAL

\author{
Maria Lília Imbiriba Sousa Colares \\ Professora Doutora da Universidade Federal do Oeste do Pará (UFOPA-PA) \\ Santarém/PA, Brasil \\ lilia.colares@hotmail.com \\ Adriana Oliveira dos Santos Siqueira \\ Mestra em Educação pela Universidade Federal do Oeste do Pará (UFOPA-PA) \\ Santarém/PA, Brasil \\ adrianaifstm@gmail.com
}

Resumo: Este artigo aborda a gestão da educação em escola de tempo integral. Objetiva analisar as concepções e práticas de educação integral e sua implicação nas ações dos gestores de escolas que desenvolveram o Programa Mais Educação (PME) da Rede Municipal de Ensino de Santarém-Pará, no período de 2009 a 2015. A pesquisa foi desenvolvida em três escolas, envolvendo seis gestores. Para o levantamento das informações se utilizou como ferramenta a entrevista semiestruturada. $O$ tratamento das informações foi realizado por meio da técnica de análise de conteúdo de Bardin (2011). Identificamos, por meio da análise, pouca clareza dos gestores escolares sobre as concepções de educação integral que norteiam suas práticas, além de revelar insipiente conhecimento sobre os fundamentos teóricos que orientam o PME. As práticas de gestão participativas apresentaram avanços como a construção do Projeto Político-pedagógico, a participação do conselho escolar e a ampliação da participação de pais e da comunidade, mas os discentes são excluídos do planejamento e das decisões da gestão escolar. A pesquisa demonstra, ainda, a necessidade de se estabelecer o debate nos espaços escolares sobre a educação integral e as práticas de gestão democráticas.

Palavras-chave: Educação integral. Programa mais educação. Gestão escolar.

This article discusses the management of full-time school education. Aims analyze the conception and practices of integral education and their implication in the actions of the managers of school that developed the More Education Program (PME) of the Municipal of Santarém-Pará, in the period from ( 2009 to 2015), They research was developed in three schools involving six managers. For the information collection was used with tool the semi-structured interview. The tratament of information was conducted by means of the technique of content analysis of Bardim (2011). We identify through the analysis little clarity of the school managers on the conceptions of integral that guide their practices, in addition to revealing incipient knowledge about the theoretical fundaments that guide PME. Participatory management practices presented as advances the construction of the pedagogical political project the participation of the School Board and the expansion of participation of parents and the community, bus the students are excluded from planning and management decision. The research demonstrates the need to settle debate in school space on the integral education and democratic management practices.

Keywords: Integral education. More education programa. School management.

Resumen: Este artículo aborda la gestión de la educación en la escuela de tiempo integral. Objetiva analizar las concepciones y prácticas de la educación integral y su participación en las acciones de los administradores de escuelas que desarrollaron el programa Más Educación (PME) de la Enseñanza Municipal de Santarém-Pará, en el período comprendido entre 2009 y 2015. La investigación fue desarrollada en tres escuelas, involucrando seis gestores. Para el levantamiento de la información se utiliza como herramienta la entrevista semi-estructurada. El tratamiento de la información se realizó mediante la técnica de análisis de contenido de Bardin (2011). Identificamos, a través del análisis, falta de claridad de los gestores de la escuela sobre los conceptos de educación integral que orientan sus prácticas, así como revelar conocimiento incipiente sobre los fundamentos teóricos que guían a los PME. Las prácticas de Gestión participativa presentaron avances la construcción del proyecto político pedagógico, la participación de la junta escolar y la ampliación de la participación de los padres y la comunidad, pero los estudiantes son excluidos de las decisiones de planificación y gestión. La investigación demuestra la necesidad de resolver el debate en espacios escolares en la educación integral y gestión democrática.

Palabras clave: Educación integral. Programa Más Educación. Gestión de la escuela.

Artigo recebido em setembro de 2017
Aprovado em novembro de 2017

Cad. Pesq., São Luís, v. 24, n. 3, set./dez. 2017 


\section{INTRODUÇÃO}

A reforma do Estado, que visa ajustar o país à realidade política, econômica e social do neoliberalismo, tem como características a redução de sua ação política e a transferência de suas ações à iniciativa privada. Nessa acepção, projetos e programas, como o Mais Educação, foram implantados, apresentando novas demandas às escolas e aos seus gestores.

O exercício da gestão revela concepções e práticas na organização da escola e na condução da ação educativa orientada por um paradigma de homem e de sociedade. Este estudo possibilitou conhecer, por meio de entrevistas com os gestores de três escolas da Rede Municipal de Ensino de Santarém/Pará, algumas dessas concepções e práticas no processo de implementação do Programa Mais Educação.

$\mathrm{Na}$ coleta das informações optou-se por adotar nomes fictícios para as escolas pesquisadas e numeração para os gestores, sendo definido o termo "gestor 1" para o gestor que estava na direção da escola no início da implantação do Programa, e "gestor 2" para o gestor que estava atuando em 2015, seguido do nome fictício da escola.

O diagnóstico das informações foi efetuado por meio da análise de conteúdo proposta por Bardin. Os procedimentos foram realizados seguindo as três fases sugeridas pela autora, quais sejam: primeira fase, que consistiu na pré-análise dos dados; segunda fase, que compreende a exploração do material coletado e transcrito; e, última fase, que se refere ao tratamento e interpretação do material coletado, transcrito e revisado (BARDIN, 2011).

Este artigo apresenta a análise e discussão do estudo empírico sobre as concepções e práticas dos gestores das escolas pesquisadas contextualizando-as no espaço amazônico, além de identificar os limites e possibilidades para o desenvolvimento de uma gestão escolar contributiva para a realização do papel da instituição educativa de promoção da formação integral do educando.

\section{CONCEPÇÕES DE EDUCAÇÃO INTEGRAL: perspectivados gestores escolares}

Gadotti (2009) apresenta duas dimensões que considera inseparáveis nas experiências de educação integral: a dimensão quantitativa - mais tempo na escola e no seu entorno - e a dimensão qualitativa - a formação integral do ser humano. Nessa compreensão, o autor identifica a escola integral, integradora e integrada na cidade, como aquela que considera o potencial educativo da cidade, dando destaque para a Escola Cidadã e a Cidade Educadora. A Escola Cidadã, participativa, apropriada pela população como parte da apropriação da cidade a que pertence, nessa acepção, supõe a existência de uma Cidade Educadora e de uma Educação Integral. Essa apropriação se dá através de mecanismos criados pela própria escola, como o Colegiado Escolar, o Conselho de Gestão Compartilhada, a Constituinte Escolar, plenárias pedagógicas, entre outros, bem como com práticas escolares que possibilitem qualificar o entendimento tanto da leitura da palavra escrita como da leitura do mundo. Para a escola ser integral, integradora e integrada na cidade, ela precisa considerar o potencial educativo da cidade.

Além da concepção do autor, outras se apresentam, cuja concepção de educação se articula a uma visão de homem, podendo contribuir para a manutenção do sistema vigente ou, de outro modo, intervir para a transformação da sociedade. Nesse contexto, situam-se, respectivamente, a concepção Liberal-Pragmatista ${ }^{1}$ e a concepção Socialista Marxista² de educação integral.

A concepção Liberal-Pragmatista, inspirada no pragmatismo de John Dewey e Anísio Teixeira, pensa a educação que pressupõe transformar a escola em uma "micro-sociedade" (CAVALIERE, 2002). Ou seja, propor uma prática escolar em que experiências reais, com fins em si mesmas e não apenas "preparatórias", ocorram em relações interpessoais e se estabeleçam em diversos níveis, nos quais os aprendizados científicos para as vidas pública e privada aconteçam de maneira integrada. As escolas-parque idealizadas por Anísio Teixeira, na década de 1950, na Bahia, e os Centros Integrados de Educação Pública (CIEPS), executadas por Darcy Ribeiro, no estado do Rio de Janeiro, na década de 1980, exerceram influência na política contemporânea de educação integral efetivada no Brasil.

A superação dessa postura reformista por uma postura revolucionária é defendida pela concepção Socialista Marxista de educação integral, que defende a ideia de formação omnilateral

\footnotetext{
11 A Concepção Liberal-Pragmatista, inspirada no pragmatismo de John Dewey e Anísio Teixeira que fundamenta a proposta do Programa Mais Educação.

2 Concepção Socialista Marxista que defende a formação omnilateral e politécnica e propõe à Pedagogia histórico-crítica uma formulação teórica que visa articular teoria e prática, mediadas pela educação.
} 
como formação integral do ser humano. Nessa educação integral do homem, a educação é apresentada como "articuladora do fazer e do pensar - a superação da monotecnia pela politecnia" (LOMBARDI, 2010 apud SILVA, 2015, p. 32). Nesse contexto, apresenta-se a pedagogia históricocrítica como uma formulação teórica que visa articular teoria e prática, mediadas pela educação.

A pedagogia do Programa Mais Educação expressa uma centralidade de diferenças culturais e busca inspiração nas elaborações do pragmatismo de John Dewey e Anísio Teixeira, sobretudo com base na compreensão desses autores acerca da impossibilidade do ensino único em uma sociedade como a do Brasil, complexa e diversa, culturalmente.

A concepção de educação integral na política pública para a educação, através do referido Programa explicita três conceitos: intersetorialidade, ampliação do tempo e espaço escolar. A intersetorialidade, trata de convergir, de forma articulada, diversas ações de atores e setores de assistência social, ciência e tecnologia, cultura, saúde, educação, esporte e meio ambiente. A ampliação da jornada escolar, com duração igual ou superior a sete horas diárias, durante todo o período letivo, com atividades educativas desenvolvidas dentro e fora do espaço escolar (MOLL, 2012).

O aspecto estruturante do PME se firma na ideia de redimensionar a organização seriada, agregando os conceitos de ciclos de formação que redimensionam os tempos de aprendizagem e de cidade educadora que reconhece o potencial da própria cidade constituída como espaço de formação humana.

Nas práticas empreendidas pelos gestores, percebe-se que há duas tendências. Um grupo que pensa em manter as atividades do Programa dentro do espaço da escola, não havendo disposição para promover a articulação com outros espaços da cidade. Depreende-se que esse grupo de gestores concebe a educação integral como uma proposta que precisa de uma superestrutura arquitetônica na escola para comportar todas as atividades previstas no Programa, como pode ser constatada nas falas dos gestores apresentadas a seguir:

[...] a escola de tempo integral é aquela que ela tem um planejamento, um funcionamento todinho com o aluno permanecendo o horário todo matutino e vespertino. Eu acho difícil na nossa realidade por conta das estruturas das nossas escolas, assim, era um dos pontos mais criticados quando o Programa foi implantado, que era a questão da estrutura que nós não tínhamos. (Gestor 1 Taperinha, 2016).

[...] aqui no nosso município não se tem uma estrutura que contemple realmente, até quem sabe até um replanejamento curricular para se atender realmente de fato a educação integral, né, porque o que a gente observa aqui é uma educação que não ocorre de fato como educação integral, mas em tempo integral por conta da própria dificuldade que acontece, né, na escola, a estrutura [...]. (Gestor 1 Lago Verde, 2016).

Assim, para o desenvolvimento das oficinas de esporte, deve ter uma quadra, salas apropriadas para as atividades de dança, música, teatro, entre outros. Na realidade das escolas públicas brasileiras, essa estrutura ideal não existe. Portanto, essas carências inviabilizam a implementação da educação integral.

Outro grupo de gestores reconhece, nas suas falas, a possibilidade de desenvolver o processo educativo em outros espaços além da escola, embora as práticas observadas nas visitas a essas escolas exemplifiquem que a interação com a comunidade se resume ao uso do espaço para desenvolver as oficinas que não puderam ser alocadas no próprio espaço da escola.

[...] quando a gente fala em educação em tempo integral a educação ela é contínua, ela é constante em todos os espaços que a pessoa vive ou convive né, tudo quanto é espaço que ela está ela aprende existe uma educação necessária e ela... assim como ela aprende ela também ensina. (Gestor 1 Lago Verde, 2016).

Hoje não dá mais, ninguém vive só. Nós estamos aí nessa coisa da rede, não é! Mas qual é o problema do Mais Educação? não é a própria concepção, mas é a mentalidade que eu tenho como gestor. (Gestor 1 Bom Jardim, 2016).

As falas dos gestores demonstram que a implementação não tem conformidade, em vários aspectos, com a concepção inclusa na legislação e nos documentos de orientação do PME. A questão posta pode ter ocorrido pela falta de conhecimento dos documentos ou pelas dificuldades que se apresentam no contexto onde a escola está inserida, como a carência de infraestrutura e de equipamentos sociais e culturais ou a logística para levar os alunos a esses espaços. 
A falta de clareza presente nas falas sobre educação integral, escola de tempo integral, educação de tempo integral remete a ausência de uma concepção clara do que é educação integral, predominando o senso comum com base na experiência e nas orientações que receberam para a implementação do Programa Mais Educação.

[...] é uma escola que vai acolher aquela criança desde o café da manhã até o lanche da tarde, até 5 horas, mas pra isso tem que ter toda uma estrutura, é um ambiente bom, uma alimentação adequada, né estudo e monitores, é, uma sala que a criança possa também tirar um cochilo, descansar, ter um espaço bacana, climatizado, né, e ter um lazer também porque não é só mandar a criança praquele espaço e dar de comer pra uma criança ter esse desenvolvimento durante o dia e é uma realidade muito distante [...]. (Gestor 2 Bom Jardim, 2016).

Eu acho que a escola integral, ela tem um tempo, ali Anísio Teixeira, depois o Brizola, né, mas a Escola é que tem esse tempo, pra ela ser integral ela depende do processo metodológico, ela depende de um conteúdo, de ações porque não é só juntar um bocado de aluno e dizer, como as vezes se faz e chamar o nome. (Gestor 1 Bom Jardim, 2016).

A inconsistência e superficialidade nas definições caracterizam a carência de discussões sobre a política bem como de um processo formativo contínuo que respondesse às constantes mudanças na equipe gestora, além da constatação de que essa política não foi construída com a participação da comunidade educativa. Ela já vem definida para ser apenas implementada.

A organização do tempo escolar foi distribuída em dois turnos: um turno de quatro horas para promover a instrução a partir do currículo definido pelo Sistema Educacional ao qual a escola está inserida; e, outro de três horas para atividades complementares definidas pelo Programa, em forma de oficinas. Esta fragmentação é compreendida como um desafio pelo gestor escolar que tenta promover o ajuste dos discentes a essa nova organização escolar, sensibilizando-o sobre a importância de sua participação nos dois turnos de atividades.

A hierarquia entre as atividades fica explícita, inclusive no imaginário dos alunos, que o tempo destinado à instrução na sala de aula é mais importante que as atividades extracurriculares. Existem outras possibilidades de organização do tempo escolar intercalando as atividades para favorecer a sua valorização, porém, isso representaria mais trabalho para a equipe gestora, como a montagem de horários e o deslocamento de alunos e professores.

A gestão da escola, responsável por mobilizar a comunidade educativa para a implementação das políticas educacionais, assume um importante papel na construção do coletivo escolar sobre os rumos da formação pretendida para os educandos.

Gramsci propõe a escola única inicial de cultura geral, humanística, com justo equilíbrio entre capacidades de operar manualmente e a capacidade de pensar - operar intelectualmente. A escola terá como uma de suas finalidades: introduzir na vida social os jovens, dotados de certa autonomia intelectual e de uma capacidade de criação intelectual bem como prática, ao mesmo tempo; e de orientação independente (MANACORDA, 2006). Nessa compreensão, a escola precisa ter um ensino mais completo, que pense o sujeito como um ser com necessidade de formação em múltiplas dimensões.

\section{PRÁTICAS DE GESTÃO E O PROGRAMA MAIS EDUCAÇÃO}

Para a identificação das práticas de gestão extraídas das falas dos gestores pesquisados tomou-se como base Libâneo (2013, p. 238, grifo do autor), que afirma:

\footnotetext{
As práticas de gestão dizem respeito a ações de natureza técnico-administrativa e de natureza pedagógico-curricular, que se constituem em meios, instrumentalidades, da ação educativa e docente. Elas se dividem em: (a) ações de natureza técnico-administrativa: a legislação escolar e as normas administrativas; os recursos físicos, materiais e didáticos, financeiros; a direção e a administração, incluindo as rotinas administrativas; a secretaria escolar, b) ações de natureza pedagógico-curricular: formulação e gestão do projeto pedagógico-curricular, do currículo, do ensino, do desenvolvimento profissional e da avaliação, ou seja, à gestão dos próprios elementos que constituem a natureza da atividade escolar.
}

A organização e a gestão da escola dizem respeito à estrutura de funcionamento, às formas de coordenação e à gestão do trabalho, ao provimento e utilização dos recursos materiais e financeiros, 
aos procedimentos administrativos, etc. visando atingir os objetivos educacionais. As práticas de gestão são os meios e as instrumentalidades da ação educativa e docente. Todos os membros da equipe escolar devem estar envolvidos com as práticas de gestão, mas a responsabilidade direta é da direção e da coordenação pedagógica.

\subsection{A gestão dos recursos financeiros e a infraestrutura como desafios à gestão escolar na educação integral}

A gestão dos recursos financeiros e a infraestrutura são parte dos desafios à gestão escolar na Educação Integral. A gestão democrática da educação prescreve uma maior integração entre a escola e a sociedade civil, que atua como controle social permitindo uma maior transparência no uso do dinheiro público. Os recursos financeiros utilizados na manutenção das atividades educativas chegam às escolas públicas por meio de programas federais, estaduais e municipais, que apresentam em suas legislações a característica da descentralização ${ }^{3}$. O repasse direto dos recursos para as escolas configura-se como desconcentração de poder.

Por conseguinte, os gestores e os partícipes do colegiado escolar têm o papel de efetivar as normatizações presentes em cada legislação. No entanto, os recursos financeiros são instrumentos importantes para a escola pública, pois viabiliza a oportunidade de cada instituição se organizar, mesmo em meio às limitações, diante de sua realidade e necessidade imediata (SANTOS; SILVA, 2016).

A fala dos gestores escolares que participaram da pesquisa reflete essa problemática. Na aplicação de recursos disponibilizados através do PDDE educação Integral - Programa Mais Educação, apresentam-se dificuldades como a definição de regras gerais prescritas no Manual Operacional de Educação Integral do MEC para aplicação do recurso que nem sempre são compatíveis com as necessidades e a realidade das escolas.

[...] o maior desafio nosso foi quando nós recebemos recurso para o Programa. Porque assim, o recurso que veio é... mediante um planejamento, né, que nós fizemos e também uma coleta de informações, né, sobre as oficinas, sobre as possibilidades de desenvolvimento dessas oficinas e as pessoas capacitadas pra isso. [...] nós solicitamos lá um recurso pra fazer oficina com horta, aí, é... quando nós fomos ver lá quais eram os critérios [...] no recurso já vinha destinado pra que seria cada valor daquele, então eles colocaram preços de algumas espécies de semente pra usar, né, de hortaliças e alguns tipos de adubo que nós não conhecíamos aqui na nossa região, então isso aí foi desafio pra comprar, né, pra implementar a oficina e também em relação a prestação de conta porque tem muita coisa, tinha muita coisa que eles usavam lá algumas nomenclaturas que nós não conhecemos aqui, de produtos que nós não conhecemos, então a gente tinha que substituir. (Gestor 1 Taperinha, 2016).

O impasse ora apresentado se repete em variados momentos do cotidiano escolar e interessa saber como o gestor age nesse cenário. Ele se conforma e simplesmente se adapta a regra estabelecida ou aciona outros mecanismos para atender às necessidades da sua realidade. Em uma instituição escolar que se baseia na prática da participação de todos os envolvidos, o colegiado escolar é um mecanismo favorável, configurando-se tanto como controle social no espaço escolar, quanto nas tomadas de decisão e compartilhamento de poder (SANTOS; SILVA, 2016). Um dos gestores pesquisados sustenta a visão de que pode unir-se ao colegiado para fazer as mudanças necessárias, flexibilizando o Programa para atender as especificidades da Escola, com o respaldo da representatividade da Comunidade Escolar.

A compreensão do referido gestor é ilustrativa dos caminhos que podem ser construídos na gestão escolar, com base na compreensão de que as políticas educacionais são implantadas com base no modelo neoliberal, mas a gestão democrática pode ser a opção na condução do dia a dia da escola, tendo em vista que tais políticas ganham materialidade na realidade onde estão sendo implementadas.

No diálogo com os gestores ficou explícito o papel do Conselho Escolar como um importante instrumento de representatividade que pode contribuir com a equipe gestora. Bravo (2014) corrobora afirmando que o caminho atual a seguir assinala o crescente envolvimento da comunidade

3 A descentralização ocorre quando há transferência do poder de decisão e autoridade com o objetivo de fortalecer a escola, levando ao controle das atividades da educação pública pelos agentes diretamente envolvidos. A desconcentração, no entanto, induz as escolas à inobservância da legislação, a equívocos nas prestações de contas e à displicência com a gestão dos seus recursos. (REZENDE, 2005). 
na organização das questões escolares, visando à melhoria de todos os processos em que se extrapolam as intenções individuais para uma gestão democrática e participativa.

Além da temática, recursos financeiros, estrutura física das escolas é outro tema muito recorrente, quando se trata das ações de natureza técnico-administrativas. As carências na estrutura física se constituíram como denúncias entre os gestores que assumiram o desafio de implementar o Programa Mais Educação, pela sua característica de ofertar atividades complementares diversificadas, cujas necessidades de espaço para a sua efetivação não foram previstas na arquitetura das Escolas. A fala do gestor 1 da Escola Taperinha (2016) resume a situação vivida nas três escolas pesquisadas.

Nós tivemos problemas, assim, de espaço, né [...] nós tivemos que tirar turmas do regular pra dar espaço para o Mais Educação né, mas assim, nós fomos arrumando os espaços aos poucos, né. Conseguimos cobrir uma área grande pra funcionar as oficinas arrumando as atividades lá no espaço, mas, assim, foi muito lento esse processo, né, mas nós conseguimos ir resolvendo aos poucos. (Gestor 1 Taperinha, 2016).

A descrição dos gestores sobre os espaços onde as atividades ocorriam indica o uso da biblioteca, sala de informática, pátio e nos arredores da escola, enfim, onde era possível alocar as oficinas, ainda que muitas vezes tivesse que comprometer o funcionamento de outras atividades que não eram do Programa. Nas situações em que não era possível arranjar-se na própria escola, então, buscava-se a parceria com a comunidade para o uso de espaço. Não obstante, a deficiência na infraestrutura das escolas, independente das necessidades suscitadas pela implantação do Programa Mais Educação, é um problema que precisa ser enfrentado.

A diversificação de atividades na implementação dessa proposta demanda por mais insumos na manutenção e funcionamento do ensino. A realidade da escola pública brasileira, especialmente a região norte, não oferece as condições de infraestrutura necessárias, sequer para a proposta tradicional de educação. Moll (2012, p. 139) fala das mudanças estruturais instituídas como tarefas a serem inseridas na agenda governamental para o processo de construção da educação integral como política pública:

\begin{abstract}
O tema da reestruturação dos espaços escolares, com ampliações, reformas, adaptações e construções constituir-se-á em agenda permanente nas próximas duas décadas, considerando-se as pendências ligadas à reestruturação da rede escolar com condições para seu funcionamento como educação em tempo integral. As demandas em termos de cozinha, refeitório, banheiro com chuveiro, quadras esportivas e salas temáticas específicas para atividades culturais no campo da leitura, da música, do teatro, do cinema, da dança e tantas outras possíveis neste alargamento de horizontes formativos, tão presentes tanto no Projeto das Escolas Parque como dos Cieps, serão pouco a pouco atendidas, na mesma medida da consolidação da política de educação integral que deverá constituir um novo padrão construtivo para as instituições educacionais. Esse processo será fruto de ações conjugadas entre os entes da União, desde que as demandas sejam explicitadas no âmbito local e vistas na perspectiva do conjunto do projeto educativo.
\end{abstract}

Essa previsão não tem se confirmado, pois os governos não promoveram as reformas necessárias, pelo contrário, a realidade atual anuncia um futuro desanimador, com propostas governamentais de redução nos gastos com a educação ${ }^{4}$. Analisando a realidade amazônica e suas especificidades, que ao longo do tempo foram pouco prestigiadas pelas ações governamentais, a situação é ainda mais preocupante. Estudos de Sampaio e Oliveira (2015) ilustram essa discrepância por região brasileira, no que se refere às condições de infraestrutura das escolas, no entanto, não há um tratamento diferenciado em relação à disponibilização de recursos, de modo a corrigir essas desigualdades.

No Brasil, há poucos indicadores consolidados que diagnosticam a desigualdade no tratamento. Na questão do financiamento, são inexistentes indicadores a nível escolar. Com relação à infraestrutura, em cada edição do Resumo Técnico do Censo Escolar, o Inep divulga a porcentagem de escolas com alguns itens de infraestrutura. Esses dados são divulgados para o Brasil e por região e são perceptíveis as desigualdades regionais. Por exemplo, em 2013, enquanto no Sul, $82,2 \%$ das escolas de Ensino Fundamental da rede pública tinham

\footnotetext{
4 Aprovação da PEC 241, em segundo turno pela Câmara de Deputados, seguindo para o Senado com nova denominação de PEC 55/2016, que prevê redução de gastos públicos pelos próximos 20 anos, inclusive para a educação.
} 
acesso à internet e $66,1 \%$ tinham quadra de esportes, no Norte, essas porcentagens para o mesmo tipo de escola eram, respectivamente, de 22,1\% e 14\%. (INEP, 2014, p. 34 apud SAMPAIO; OLIVEIRA, 2015, p. 521).

A sinergia de vários ministérios, instituições e setores (intersetorialidade) de mobilizar forças para otimizar recursos, visando a melhoria da qualidade do ensino, tal como indicado na legislação e em documentos de orientação do Programa Mais Educação (BRASIL, 2007) não se concretiza no âmbito da escola para suprir essas lacunas, especialmente na infraestrutura, porque é uma inovação proposta dentro de uma cultura organizacional, com experiências e práticas setoriais que atuam de forma isolada. Isto posto, constata-se uma incongruência entre a proposta da política educacional e às condições de sua efetivação.

O financiamento do PME é feito por meio do Programa Dinheiro Direto na Escola (PDDE/ Educação Integral), mas não prevê construções de maior porte que atendam às necessidades. Os recursos são destinados à Unidade Executora de cada escola e liberados em duas parcelas para custeio (alimentação e transporte dos monitores do Programa), capital e custeio (contratação de serviços, material de consumo e permanente para a escola) e kits pedagógicos para as oficinas (custeio e capital) ${ }^{5}$.

A superação das desigualdades regionais supracitadas e a sustentação de recursos são necessárias para que a escola cumpra o seu papel pedagógico e assuma a sua responsabilidade de garantir a educação equitativa e de qualidade. "Em um contexto de autonomia, se a equidade não é observada, sem dúvida, as desigualdades serão acentuadas. É preciso garantir a todos oportunidades iguais de aprendizagem" (BRAVO, 2014, p. 18).

Os desafios apresentados, ainda que tornem precária a implementação da proposta, não são obstáculos intransponíveis aos gestores que buscam alternativas para solucionar tais carências, afim de não perder o recurso do Programa muito bem-vindo no contexto de tantas demandas e necessidades que se apresentam no dia a dia da escola, seja construindo parcerias com a comunidade para uso de espaços, ou reorganizando o espaço da escola para acomodar as atividades das oficinas. E assim, a gestão escolar vai ressignificando suas ações, em meio às adversidades.

\subsection{A ampliação da jornada escolar diária e a gestão das ações de natureza pedagógico- curriculares}

O Decreto $n^{\circ} 7.083$, de 27 de janeiro de 2010, que dispõe sobre o Programa Mais Educação, trata em seu Art. $1^{\circ}$ sobre a finalidade do referido Programa: "contribuir para a melhoria da aprendizagem por meio da ampliação do tempo de permanência de crianças, adolescentes e jovens matriculados em escola pública, mediante oferta de educação básica em tempo integral" (BRASIL, 2010). Nesse sentido, destaca-se o conceito de educação básica em tempo integral como sendo a jornada escolar com duração igual ou superior a sete horas diárias, durante todo o período letivo, compreendendo o tempo total em que o aluno permanece na escola ou em atividades escolares em outros espaços educacionais.

A implementação do Programa Mais Educação, nesse formato, apresenta novos desafios à gestão escolar em suas dimensões administrativa e financeira, como já foi abordado, mas também, na dimensão pedagógica que podem ser compreendidas de forma inter-relacionadas. As práticas de gestão vão se construindo no ambiente escolar, as quais são explicitadas nas falas dos gestores entrevistados, no que concerne as implicações pedagógicas de ampliação da jornada escolar e da relação escola/família/comunidade.

Há que se destacar o papel do gestor. A preparação para o exercício da gestão vai além do domínio de conhecimentos de natureza técnica sobre administração, legislação e planejamento. Embora esses conhecimentos sejam extremamente importantes, ganharão sentido e significado se contextualizados no ambiente escolar, a partir da dinâmica que envolve diferentes sujeitos e subjetividades, demandando ao gestor a capacidade de analisar situações, fundamentar suas decisões e resolver os problemas que se apresentam, de forma legal e ética (COSTA; LIMA; LEITE, 2015, p. 75).

5 O Manual Operacional de Educação Integral define custeio como material de consumo e serviços, e capital como aquisição de bens ou materiais permanentes. (BRASIL, 2014). 
A seleção dos alunos para participar da jornada ampliada foi uma das questões apresentadas aos gestores, pois o Programa não contemplava todos os alunos da escola, mas um grupo restrito que nas escolas locus do estudo variava entre 100 e 150 alunos. Os principais critérios para a seleção explicitam o assistencialismo que caracteriza o PME, quais sejam: a participação em programa de distribuição de renda, alunos de origem familiar desestruturada e em situação de risco.

Essa realidade é tratada por Moll (2012) como discriminação positiva, atuando como política afirmativa que incide em contextos de vulnerabilidade social e educacional, como parte das estratégias de enfrentamento das desigualdades sociais. A educação integral, nessa perspectiva, não está acessível a todos, dando à educação um caráter regenerador quando tem a intenção clara de oferecer uma ocupação que tire a criança da rua e das situações de risco. Paro et al. (1988, p. 202) disserta sobre a dimensão assistencial presente nos projetos recentes de expansão do tempo diário de escolaridade oferecido aos alunos de escolas públicas:

\footnotetext{
Nesses projetos, argumenta-se que a extensão sugerida é desejável não só para que os alunos possam aprender mais e melhor, mas também para que, nesse espaço, possam ser mais bem alimentados, mais bem cuidados (inclusive no que diz respeito às questões de saúde) e mais protegidos dos 'perigos da rua'. Por outro lado, os segmentos da população a que esses projetos se dirigem têm-se mostrado aparentemente receptivos às propostas de extensão do período diário de escolaridade.
}

As carências, de toda ordem, que se apresentam na realidade dos educandos matriculados na escola pública, especialmente dos bairros periféricos, não podem ser negadas. Nesse contexto, as políticas assistencialistas não deixam de ser uma oportunidade de proporcionar a essas crianças o acesso a recursos mínimos ofertados pela escola, os quais a condição econômica familiar não permite oferecer, por consequência das desigualdades sociais. Os recursos acessados por meio de programas, como o Mais Educação, trazem benefícios a essas crianças e adolescentes. A fala do gestor da Escola Lago Verde, que se repete também nos depoimentos de outros gestores pesquisados, demonstra a receptividade das famílias ao Programa:

Mais Educação, ele é muito positivo[...] ele é positivo para as famílias [...] em que o filho [...] que o pai por exemplo não tem onde deixar o filho, o filho vai, tá aqui na escola e ele vai tá recebendo uma educação diferenciada, ele vai tá recebendo uma alimentação adequada é [...] é lanche [...] é almoço [...] é lanche [...] tudo isso antes dele ir pra casa, então de uma certa maneira contribui com a família de um modo geral que o pai fica despreocupado porque ele tá na escola [...] tá no Mais Educação [...] ele está despreocupado. (Gestor 2 Lago Verde, 2016).

A discriminação positiva, presente nessa fala, vai ao encontro das crianças em situação de risco. Leclerc e Moll (2012, p. 23) explicitam a justificativa de priorizar o público vulnerável ao afirmarem que "crianças, adolescentes e jovens em contextos de vulnerabilidade têm suas liberdades cerceadas, em um ciclo que muitas vezes se estende à vida adulta e em cadeia intergeracional". Em uma sociedade desigual, na qual o pertencimento étnico, de classe, gênero e orientação sexual são fatores determinantes para o acesso à ciência, à cultura e à tecnologia, a vulnerabilidade é marcada pelas violências simbólicas e físicas. Daí vem a importância desse atendimento para minimizar os impactos dessas desigualdades.

O reconhecimento da importância de oferecer na escola condições de assistência à criança para garantir a sua aprendizagem, nas condições atuais, deve imbuir-se de uma postura problematizadora do contexto mais amplo da estrutura capitalista que gera tamanhas desigualdades.

Ferreira e Colares (2016) advertem que, pensar no tempo integral nas escolas, incide levar em consideração as variáveis do tempo, espaço e oportunidades de aprendizados, pois, quando as iniciativas educacionais se limitam a ampliar o tempo escolar em função do assistencialismo, apenas para suprir as carências, sejam elas, sociais ou financeiras de alguns indivíduos, sem ofertar-lhes a formação ética, estética e intelectual, estaremos apenas oportunizando mais tempo do mesmo tempo, perpetuando a visão fragmentada da realidade sem compromissos reais com a formação emancipadora.

A carência de infraestrutura como banheiros inadequados, por exemplo, criava algumas situações que geravam a descontinuidade do tempo integral, porque a criança tinha que ir até a sua casa e depois retornar à escola para dar sequência às atividades. Para muitos pais, essa situação 
gerava um estresse para as crianças e, por isso, demonstravam resistência em participarem do Programa.

Adescrição dos gestores e a observação do funcionamento do Programa, a partir de documentos como atas e relatórios disponibilizados pela Escola, demonstraram que o funcionamento da escola dividia-se em dois turnos, tanto quando o Mais Educação estava funcionando no contraturno, quanto no turno intermediário; um identificado como turno regular com as atividades do Programa de Ensino do Sistema Educacional da Rede Municipal previstas para o Ensino Fundamental e o outro turno com a jornada ampliada, no qual aconteciam as atividades complementares através de oficinas.

O estudo de Menezes e Leite (2012) aponta para essa questão, ao revelar que a maioria das experiências de ampliação da jornada ocorre no contraturno escolar. As autoras advertem que essa forma de organização, de um turno funcionando como "escola regular" e outro como "jornada ampliada", caso ocorram sem a devida articulação entre os turnos, pode levar ao aparecimento de "duas escolas" dentro da mesma unidade escolar. A diversidade de situações postas pela ampliação da jornada escolar exige do gestor a capacidade de acolhimento das diferentes demandas que surgem no contexto e nas dinâmicas de trabalho, com suporte na escuta dos diferentes sujeitos da comunidade escolar para promover o planejamento e as ações, de forma integrada, tendo em vista a formação ampla dos educandos.

\subsection{A integração do PME na escola e a participação da comunidade}

A construção da proposta formativa que promova a unidade do processo educacional na escola não é uma tarefa fácil. Na realidade das escolas estudadas percebeu-se obstáculos que interferem nessa construção, tais como: a falta de uma concepção clara sobre educação integral e extensão da jornada escolar, a resistência dos professores, a coexistência de crianças em jornada ampliada com alunos em um só turno, que não participavam das atividades do Programa Mais Educação e a inadequada estruturação do espaço escolar para o atendimento educacional em tempo ampliado.

A implantação de um Programa que foi construído sem a participação dos principais envolvidos no processo, gestores, professores, pais e alunos gera desconfiança e dificuldade na adesão, principalmente porque apresenta demandas de trabalho que fogem do convencional, para as quais nem sempre a escola está preparada. "A articulação e a integração dos corpos docente, técnico e administrativo das propostas de tempo integral ainda carecem de definições de ordem pedagógica e administrativa" (ARCO-VERDE, 2012, p. 94).

A integração e a articulação entre meios e objetivos educacionais, embora sejam da responsabilidade de todos os membros da equipe escolar, são a direção e à coordenação pedagógica que respondem de forma mais direta pelas condições e meios de realização do trabalho dos professores na sala de aula" (LIBÂNEO; OLIVEIRA; TOSCHI, 2012, p. 426). É desejável, portanto, que a coordenação pedagógica, cujo papel é desempenhado pelo pedagogo escolar, viabilize a integração e articulação com os professores.

Nas escolas pesquisadas, uma das questões impostas ao pedagogo e ao gestor era trabalhar com os diferentes perfis do grupo de educadores. Os oficineiros, cuja forma de provimento à função não exige formação prévia ou experiências docentes para ministrarem as atividades e os professores de carreira, temporários ou efetivos. A atuação do coordenador pedagógico e a sua importância para a integração do programa foi destacada na fala do gestor 1 da escola Bom Jardim:

É o envolvimento dos oficineiros com os professores, interação pra troca porque eu achava que [...] por exemplo, no recurso humano que entra a [Coordenadora Pedagógica], que é formidável. Os alunos estavam com dificuldade... os alunos estão silabando, esses aqui [...] esses outros aqui leem palavra por palavras, estes com fluência [...] esse mapeamento que a [Pedagoga] fazia, que era a minha coordenadora pedagógica, subsidiava o trabalho dos oficineiros... então olha vocês vão trabalhar por aqui. Nós não vamos repetir, nós não vamos perder tempo. (Gestor 1 Bom Jardim, 2016).

O relato do gestor demonstra uma mediação do pedagogo junto aos dois grupos de educadores (professores do turno regular e os oficineiros do PME), na busca pela integração, em que há uma preocupação com a oficina de letramento. No diálogo com os gestores, constata-se a focalização em objetivos estritamente cognitivos, desprezando aspectos importantes do propósito educativo como a socialização, a autonomia, o desenvolvimento da criatividade, enfim, não há uma percepção das possibilidades que podem ser exploradas, tendo em vista as diversas oficinas oferecidas na escola 
para o desenvolvimento integral compreendido como um estado no qual todas as necessidades humanas devem emergir no processo educacional, tais como "a busca pela sobrevivência, o prazer, a criação e o gozo da cultura, a participação na vida social, a interação com os outros homens, a auto-realização e a autocriação" (LOMBARDI, 2011, p. 362).

A dificuldade para promover a integração pode ter ocorrido pela falta de uma concepção clara de educação integral e até pelo desconhecimento das diretrizes e dos objetivos do Programa pelos implementadores, gerando uma falta de articulação dessa proposta de educação integral com o ensino regular e o Projeto Político-pedagógico da escola. Esse distanciamento se apresenta em forma de conflitos, como a resistência dos professores em aceitar e colaborar com a implementação da proposta. No discurso dos gestores fica explícita essa resistência:

[...] a priori houve muita dificuldade, a questão da aceitação foi um pouco complicada aqui na escola, então nós tentávamos sempre respaldar os professores que o Programa é uma parte [...] o Programa era uma forma de qualificar, de tentar melhorar o rendimento dos nossos alunos [...] (Gestor 1 Lago Verde, 2016).

[...] outro desafio nosso era a questão da resistência do próprio professor, porque o pai acredita, o aluno acredita, o pai de santo acredita, mas o professor que está ali não quer sair da sua zona de conforto. Ele me deu trabalho na época. Eles não acreditavam, mas aos poucos foi uma questão de conquista [...] (Gestor 1 Bom Jardim, 2016).

Estas falas revelam a necessidade do gestor com a equipe pedagógica em assumirem um novo estilo de gestão, que para Bravo (2014) está comprometido com a qualidade e tem a marca da participação. "O gestor é líder, facilitador, induz o grupo a atingir os objetivos e resultados. Cada membro da equipe é importante e tem contribuições a dar. O poder é repartido, bem como as responsabilidades" (BRAVO, 2014, p. 67).

Assim, a resistência à mudança, a indiferença, as atitudes não cooperativas e outras manifestações negativas podem dar lugar a existência de uma relação positiva entre o grau de participação e os sentimentos de satisfação, responsabilidade e comprometimento.

Os pais são os principais beneficiários e, por isso, devem ser chamados a participar. Promover e gerir essa relação escola-família não é uma tarefa fácil para os gestores escolares, por causa das diferenças de pensamento e da falta de consenso que, muitas vezes, permeiam essa relação. Há, muitas vezes, o medo de compartilhar com a família o poder de decisão, ou a falta de interesse da família de participar da vida da escola. O desafio é como estreitar essa relação visando à melhoria no processo de formação dos educandos. Na realidade pesquisada, ficou evidente a diferença de percepção dessa relação família-escola como descrito nos relatos a seguir:

O que foi mais desafiador?! Como nós precisávamos até então da autorização, é, da autorização dos pais pra esse programa, né, foi bem desafiador a questão da presença dos pais, da participação dos pais até mesmo pra autorizar essa questão do aluno no Programa Mais Educação, então tivemos que fazer uma assembleia, um ofício circular, convocando esses pais pra estarem presentes aqui na escola pra fazer os esclarecimentos. Por sinal até hoje nós temos essa dificuldade grande, né, de pais aqui na escola, né, da participação. (Gestor 1 Lago Verde, 2016).

E no que eu acredito! Se você abrir a escola [...] olha como eu fico! [...] [arrepiado] [...] a porta, a família entra e eles te ajudam. Eles querem ajudar, eles querem contribuir, eles querem até financeiramente se faltar o gás, alguma coisa, uma merenda ... mas, a gente tem aquela resistência de achar que vai perder o poder [...] (Gestor 1 Bom Jardim, 2016).

Os relatos apresentados explicitam duas formas diferentes de conceber a participação da família na escola. O primeiro que ressalta a falta de interesse dos pais pelo que acontece na escola, e o segundo que aposta na adesão dos pais quando a eles são oferecidas oportunidades de participação. Para além da garantia da gestão participativa, a necessidade de trazer os pais para a escola se justifica pela contribuição que podem dar para o alcance do objetivo de promover a aprendizagem do educando.

O desinteresse dos alunos é um dos principais desafios que requer da escola pública competência para ensinar, levando em conta a necessidade de seduzir, de despertar o interesse 
para que eles possam aprender. A escola não tem dado a devida importância para o que acontece fora e antes dela, com seus educandos.

Assim, a escola que toma como objeto de preocupação levar o aluno a querer aprender precisa ter presente a continuidade entre a educação familiar e a escolar, buscando formas de conseguir a adesão da família para sua tarefa de desenvolver nos educandos atitudes positivas e duradouras com relação ao aprender e ao estudar (PARO, 2005, p. 66).

Com isso, depreende-se que a participação dos pais vai além da realização de reparos, serviços de limpeza, preparação da merenda, ou cumprimento de tarefas em festas ou outras atividades escolares, embora não se deva negar que estas oportunizam o acesso às informações sobre 0 funcionamento da escola e estreitam as relações. Contudo, além da participação na execução, que seja oportunizada a partilha nas decisões, essa participação autônoma é muitas vezes questionada com o argumento de que os pais são ignorantes no que concerne aos aspectos pedagógicos.

Por outro lado, a escola se contradiz no seu discurso quando exige que os pais participem da formação dos seus filhos, auxiliando nas atividades escolares, o que se constitui em uma tarefa pedagógica. Isso não significa dizer que os pais estão totalmente preparados para exercerem a gestão democrática, e refletindo bem, muitas vezes, nem mesmo os professores e demais segmentos da comunidade estão. Como disserta Paro (2016), a participação democrática não se dá espontaneamente, sendo antes um processo histórico de construção coletiva, para o qual se coloca a necessidade de prever mecanismos institucionais que não apenas viabilizem, mas também incentivem práticas participativas dentro da escola pública.

A maneira como é compreendida a relação entre escola e comunidade não é um consenso entre os gestores. Alguns veem a relação escola-comunidade como uma possibilidade de a escola usufruir de algum espaço ou serviço que a comunidade possa oferecer. Mas, há também quem perceba que a parceria tem reciprocidade, em que a escola recebe, mas também se abre para a comunidade.

A interação com a comunidade, ora bilateral, ora unilateral, foi estimulada com a implantação do Programa Mais Educação. A mudança dos tempos escolares que interfere diretamente na organização familiar, aproxima a família da escola oferecendo uma possibilidade real de ampliar a qualidade da gestão democrática e da tomada das decisões com a participação dos pais e responsáveis. "A família, assim como a escola de tempo integral, está aprendendo a lidar com as novas situações de tempo e a criar novas formas que se estabelecerão como uma nova cultura escolar e familiar" (ARCO-VERDE, 2012, p. 94).

As reflexões apresentadas até aqui corroboram a participação da comunidade escolar como prática importante para a efetivação da gestão democrática. Nesse contexto, fala-se da equipe gestora, dos professores, dos oficineiros, dos pais e da comunidade. Um sujeito importante que integra a comunidade escolar, para o qual se destina a razão de existir da instituição educativa fica oculto nessa contextura. No diálogo com os gestores, não se evidencia a voz do aluno, com exceção de uma situação em que os gestores falam das oficinas que mais agradam e as oficinas menos atrativas aos educandos.

Se o aluno é o sujeito presente, o grande questionamento que se coloca é do porquê se nega a ele a participação no planejamento e na organização da escola. Segundo Aranha (2006) uma gestão que se pretende democrática leva a escola a refletir sobre seus alunos, reconhecendo-os enquanto sujeitos socioculturais e busca de maneira contínua, integrada à realidade da escola, a explicitação, contribuição, participação de toda a comunidade escolar, cujo processo os alunos também estão inseridos. Cavaliere (2007, p. 1.029) corrobora esse pensamento destacando o papel emancipatório da concepção democrática da escola em tempo integral:

[...] a concepção democrática de escola de tempo integral imagina que ela possa cumprir um papel emancipatório. O tempo integral seria um meio a proporcionar uma educação mais efetiva do ponto de vista cultural, com o aprofundamento dos conhecimentos, do espírito crítico e das vivências democráticas. A permanência por mais tempo na escola garantiria 
melhor desempenho em relação aos saberes escolares, os quais seriam ferramentas para a emancipação.

No ato educativo, tendo como ponto de partida o reconhecimento do aluno enquanto sujeito sociocultural, deve-se estabelecer um diálogo de saberes para não repetir o mesmo erro da tradicional educação bancária que tratava o aluno como "deficiente cultural" porque não traz em sua bagagem a "linguagem culta" valorizada pela escola. Mas, para isso, é preciso reconhecer as diferenças. Segundo Colares (2012, p. 51) o reconhecimento do outro é condição fundamental para que se construa uma sociedade plural, mas não é possível reconhecer o que não se conhece, pois "dizer que uma criança é de favela, que é ribeirinha, não nos leva a compreendê-la, afinal: o que é ser de favela? O que é ser ribeirinho?". Isto posto, o processo de conhecimento necessário passa pela compreensão da natureza do contato entre sujeitos diferentes e dos campos políticos que os envolvem.

Em suma, um processo de gestão que construa coletivamente um projeto pedagógico de trabalho tem, na raiz, a potência da transformação. A gestão escolar deve ter coerência com esses objetivos em suas concepções e práticas para constituir-se em um diferencial no processo de construção de uma sociedade mais justa, com qualidade social referenciada.

\section{CONSIDERAÇÕES FINAIS}

As experiências em curso, no Brasil, divergem em diversos aspectos. O Programa Mais Educação é representativo nesse campo. Ainda que apresente limitações quanto a universalização do atendimento, o PME é a principal política implementada na Rede Municipal de Ensino, na cidade de Santarém/PA, para a promoção da educação integral.

As concepções antagônicas Liberal Pragmatista e Socialista Marxista de educação integral já destacadas, não se apresentaram de forma clara nas falas dos pesquisados que demonstraram ter pouca clareza sobre concepções de educação integral que norteavam suas práticas, além de revelar pouco conhecimento sobre os fundamentos teóricos que orientam o Programa Mais Educação. O percurso entre a concepção das propostas e a implementação na instituição escolar, sofreu variações, seja pelas condições locais, seja pelo pouco conhecimento das diretrizes que nortearam o PME.

Ainda assim, algumas características da concepção original do PME foram assimiladas, como o caráter assistencialista que reforça o duplo papel da escola do "proteger e educar" que se apresenta como política de discriminação positiva e as limitações pedagógicas, que segundo Santos e Prado (2014) concentram a importância nos componentes curriculares de Língua Portuguesa e Matemática, que mesmo no tempo dedicado às atividades complementares, que deveriam oferecer atividades mais prazerosas, aparecem como atividades obrigatórias.

Na perspectiva da atuação pedagógica, visando integrar as atividades entre os turnos "regular" e "complementar", não se percebeu o reconhecimento das inúmeras possibilidades que podem ser exploradas, tendo em vista as diversas oficinas oferecidas na escola.

Nas práticas empreendidas pelos gestores, reveladas na análise dos discursos dos sujeitos pesquisados, foram encontradas características que se aproximavam da gestão democrática, tais como: construção participativa do PPP, participação do conselho escolar, parcerias da escola com a comunidade. Por outro lado, foram encontradas características que se distanciavam da gestão democrática, tais como: a ausência de participação dos alunos e a gestão financeira de recursos com participação reduzida e pouca transparência.

No que diz respeito à compreensão do que seja espaço educativo, dois conceitos são identificados na análise do discurso dos sujeitos dessa pesquisa, o primeiro de que a ação educativa deve ocorrer dentro dos muros da escola, que deverá ser estruturada para receber a educação em tempo integral; e o segundo, que parte da compreensão de que existem outros espaços, além da escola, com possibilidade de desenvolvimento da prática educativa.

As dificuldades de integração do Programa com a proposta pedagógica constituíram-se em uma das problemáticas reveladas no estudo e podem ter ocorrido pela falta de uma concepção clara de educação integral e até pelo desconhecimento das diretrizes e dos objetivos do Programa pelos implementadores, gerando uma falta de articulação dessa proposta de educação integral com o ensino regular e o Projeto Político-pedagógico da escola. Esse distanciamento se apresentou em 


\section{Maria Lília Imbiriba Sousa Colares e Adriana Oliveira dos Santos Siqueira}

forma de conflitos, como a resistência dos professores em aceitar e colaborar com a implementação da proposta.

A compreensão da ação educativa como uma atividade dinâmica e contraditória permite perceber que, mesmo diante das adversidades, a gestão escolar pode ressignificar suas ações com a atuação democrática, sobretudo na construção do Projeto Político-pedagógico que promova a unidade do processo educacional na escola.

Consoante à proposição de Paro (2016), a participação democrática não se dá espontaneamente, sendo antes um processo histórico de construção coletiva, para o qual se coloca a necessidade de prever mecanismos institucionais que não apenas viabilizem, mas também incentivem práticas participativas dentro da escola pública.

As análises referentes à participação evidenciaram pontos frágeis tais como a participação do aluno, que comprometem a efetivação da gestão democrática despotencializando o seu poder mobilizador de construção de uma proposta educativa para a formação do ser humano em toda a sua completude.

É desejável que o construto, em questão, seja fruto da mobilização coletiva por uma educação integral e em tempo integral na Amazônia, feita para a Amazônia e pela Amazônia, que valorize o conhecimento local, sem desconsiderar o universal. Que promova o empoderamento pelo acesso ao conhecimento historicamente acumulado e aos bens tecnológicos. Que assuma a participação efetiva na tomada de decisão, como exercício a ser praticado cotidianamente, no sentido de proporcionar à população, principalmente às classes menos favorecidas, uma educação emancipatória. Que valorize a diversidade e as especificidades amazônicas, que através de processos educacionais e pedagógicos, propicie o repensar crítico sobre a diversidade, de maneira a promover o respeito e a valorização de todas as formas de manifestação cultural. Este é o desafio posto à gestão escolar democrática: construir uma proposta de educação integral em tempo integral, fundamentada nas formulações da pedagogia histórico-crítica, comprometida com a articulação teoria e prática, mediadas pela educação, capaz de contribuir para a formação omnilateral e politécnica, visando à emancipação e a transformação social. 


\section{REFERÊNCIAS}

ARANHA, M. L. de A. História da educação e da pedagogia: geral e do Brasil. 3. ed. rev. e ampl. São Paulo: Moderna, 2006.

ARCO-VERDE, Y. F. de S. Tempo escolar e organização do trabalho pedagógico. Em Aberto, Brasília, DF, v. 25, n. 88, p. 83-97, jul./dez. 2012.

BARDIN, L. Análise de conteúdo. São Paulo: Edições 70, 2011.

BRASIL. Decreto $\mathrm{n}^{0} 7.083$, de 27 de janeiro de 2010. Dispõe sobre o Programa Mais Educação. Diário Oficial da União. Brasília, DF, 27 jan. 2010.

. Ministério da Educação. Secretaria de Educação Básica. Diretoria de Currículos e Educação Integral. Manual operacional de educação integral. Brasília, DF: MEC; SEB; DICEI, 2014.

Portaria Normativa Interministerial $n^{0} 17$, de 24 de abril de 2007. Institui o Programa Mais Educação, que visa fomentar a educação integral de crianças, adolescentes e jovens, por meio do apoio a atividades sócio-educativas no contraturno escolar. Diário Oficial da União, Brasília, DF, 26 abr. 2007. Disponível em: <http://portal.mec.gov. br/arquivos/pdf/mais educacao.pdf>. Acesso em: 4 ago. 2016.

BRAVO, I. Gestão educacional no contexto municipal. 2. ed. Campinas, SP: Alínea, 2014.

CAVALIERE, A. M. V. Educação integral: uma nova identidade para a escola brasileira? Educ. Soc., Campinas, v. 23, n. 81, p. 247-270, dez. 2002. Disponível em: <http://www.cedes.unicamp.br>. Acesso em: 28 jan. 2016.

CAVALIERE, A. M. V. Tempo de escola e qualidade na educação pública. Educação e Sociedade, Campinas, v. 28 , n. 100 , p. 1015-1035, 2007. Número especial.

COLARES, A. A. Educação na Amazônia: o papel do gestor na melhoria dos processos educacionais. In: COLARES, M. L. I. S.; XIMENES-ROCHA, S. H.; COLARES, A. A. (Org.). Gestão democrática: a escola pública e a formação continuada como objeto de análise. Belém: GTR, 2012.

COSTA, E. A. da S.; LIMA, M. do S. L.; LEITE, M. C. da S. R. Construção da profissionalidade do gestor escolar: concepções e práticas. RBPAE, v. 31, n. 1 , p. 65-84, jan./abr. 2015.

FERREIRA, G. V.; COLARES, M. L. I. S. Educação de tempo integral em Santarém: ressignificação curricular na Secretaria Municipal de Educação. In:
COSTA, S. A. da; COLARES, M. L. I. S. (Org.). Educação integral: concepções e práticas a luz dos condicionantes singulares e universais. Curitiba: CRV, 2016.

GADOTTI, M. Educação integral no Brasil: inovações em processo. São Paulo: Instituto Paulo Freire, 2009. (Educação cidadã, 4).

LECLERC, G. de F. E.; MOLL, J. Educação integral em jornada diária ampliada: universalidade e obrigatoriedade?. Em Aberto, Brasília, DF, v. 25, n. 88, p. 17-49, jul./dez. 2012.

LIBÂNEO, J. C.; OLIVEIRA, J. F. de; TOSCHI, M. S. Educação escolar: políticas, estrutura e organização. 10. ed. rev. ampl. São Paulo: Cortez, 2012. (Coleção docência em formação: saberes pedagógicos).

LIBÂNEO, J. C. Organização e gestão da escola: teoria e prática. 6. ed. rev. e ampl. São Paulo: Herccus, 2013.

LOMBARDI, J. C. Algumas questões sobre educação e ensino em Marx e Engels. Revista Histedbr, Campinas, p. 347-366, abr. 2011. Número especial.

MANACORDA, M. A. História da educação: da antiguidade aos nossos dias. 12. ed. São Paulo: Cortez, 2006.

MENEZES, J. S. da S.; LEITE, L. H. A. Ampliação da jornada escolar em municípios brasileiros: políticas e práticas. Em Aberto, Brasília, DF, v. 25, n. 88 , p. 53-68, jul./dez. 2012.

MOLL, J. A agenda da educação integral: compromissos para sua consolidação como política pública. In: . Caminhos da educação integral no Brasil: direito a outros tempos e espaços educativos. Porto Alegre: Penso, 2012.

PARO, V. H. Administração escolar e qualidade do ensino: o que os pais ou responsáveis tem a ver com isso? In: BASTOS, J. B. (Org.). Gestão democrática. 4. ed. Rio de Janeiro: DP\&A; SEPE, 2005.

PARO, V. H. et al. Escola de tempo integral: desafios para o ensino público. São Paulo: Cortez; Autores Associados, 1988.

PARO, V. H. Gestão democrática da educação pública. 4. ed. São Paulo: Cortez, 2016.

REZENDE, V. M. Descentralização ou desconcentração?: o controle dos gastos com a educação: uma ação que supera a autonomia da escola. In: REUNIÃO ANUAL DA ASSOCIAÇÃO NACIONAL DE PÓS-GRADUAÇÃO E PESQUISA EM EDUCAÇÃO, 28., 2005, Caxambu-MG. Anais... Caxambu 
-MG: ANPEd, 2005. Disponível em: <http://28reuniao.anped.org.br/>. Acesso em: 25 mar. 2010.

SAMPAIO, G. T. C.; OLIVEIRA, R. P. de. Dimensões da desigualdade educacional no Brasil. RBPAE, Brasília, DF, v. 31, n. 3, p. 511-530, set./dez. 2015.

SANTOS, I. M. dos; PRADO, E. C. do. A gestão da educação e o Programa Mais Educação. Educação em Perspectiva, Viçosa-MG, v. 5, n. 1, p. 156-173, jan./jun. 2014.
SANTOS, I. M. dos; SILVA, G. da. O papel do colegiado escolar na gestão financeira da escola pública. Revista Exitus, Santarém, PA, v. 6, n. 1, p. 7789, jan./jun. 2016.

SILVA, P. A. D. da. Omnilateralidade e as concepções burguesas de Educação Integral. Revista HISTEDBR, Campinas, n. 65, p. 218-227, out. 2015. Disponível em: <www.fe.unicamp.br/revistas/ged/ histedbr/article/view/7358/6175>. Acesso em: 4 jan. 2016. 